The skiagram was usually commented on correctly, but some were very vague about the nature of various contours of the heart shadow. Most candidates recognized the electrocardiogram.

The second case was a middle-aged man with a moderate degree of mitral stenosis and auricular fibrillation. Here the ventricular rate was well controlled by digitalis. In consequence the arrhythmia was misdiagnosed fairly often, some thinking that extra-systoles only were present. Sometimes with slow ventricular rate the irregularity is slight, but that there is never true regularity should always be recognizable on car eful observation. Acceleration of the heart rate will always make the irregularity more obvious. The mitral lesion was not always correctly assessed. Owing to the presence of auriculation fibrillation only the murmur in the earlier part of diastole was heard. Not many candidates took advantage of the procedure of turning the patient on the left side in order to increase the loudness of the murmur.

In this case the degree of precordial thrust over the right ventricle was not always correctly appreciated.

The associated recession of the intercostal spaces just outside the left border of the heart was mistaken for systolic retraction and an adherent pericardium diagnosed.

The electrocardiogram was for the most part correctly interpreted.

These two cases should have presented no real difficulties if accurate examination and investigation of the physical signs had been carried out.

\title{
A CASE OF DIABETES WITH CHRONIC PULMONARY TUBERCULOSIS AND SYPHILITIC AORTITIS.
}

\author{
By PHILIP ELLMAN, M.D., M.R.C.P., \\ Physician-in-Charge of Tuberculosis Dept. and Chest Clinic, East Ham.
}

THIS case was shown by me to the M.R.C.P. candidates primarily as a chest case. In order to assist candidates with the limited time at their disposal, I told them that the patient had diabetes and a positive Wassermann. With few exceptions I found that the candidates diagnosed either pulmonary tuberculosis or syphilitic aortitis, but not both.' The patient was a man in the 50's, with a very suggestive history of chronic chest disease. I think the reason why the complete diagnosis was missed was because of the faulty method of examining chest cases ; most candidates proceeded at once to examine the lungs. It is essential in all chest cases to make an examination of the heart first, especially with regard to its size and position. Had this been done one feels certain that the aortitis would not have been missed. It must be admitted that the physical signs of the aortitis were few, although the characteristic ringing aortic second sound was beyond question and was the clue to the diagnosis. With regard to the lungs, most candidates had diagnosed the lesion in the right upper zone as a fibroid lung. This of

\footnotetext{
1 In addition the patient was a tabetic with Charcot's knees.
} 
course, whilst correct, was extremely vague and the decision as to whether it was tuberculous and non-tuberculous fibrosis was not elicited without close questioning.

I was astonished to find how few students asked, in addition to the results of their medical clinical examination, for further information $(a)$ with regard to bacteriological results of sputum ; and $(b)$ for an X-ray film of the chest. They were perfectly justified in doing so after clinical examination had been completed. The term fibroid lung in this case was naturally vague, as there were obvious signs of a large cavity which had been missed by certain candidates. It is unnecessary to go into the signs of cavity in this brief account, but I would stress the importance of candidates familiarizing themselves with the characteristics of normal and abnormal breath sounds, because it is often the most elementary points that the candidates appear to have forgotten.

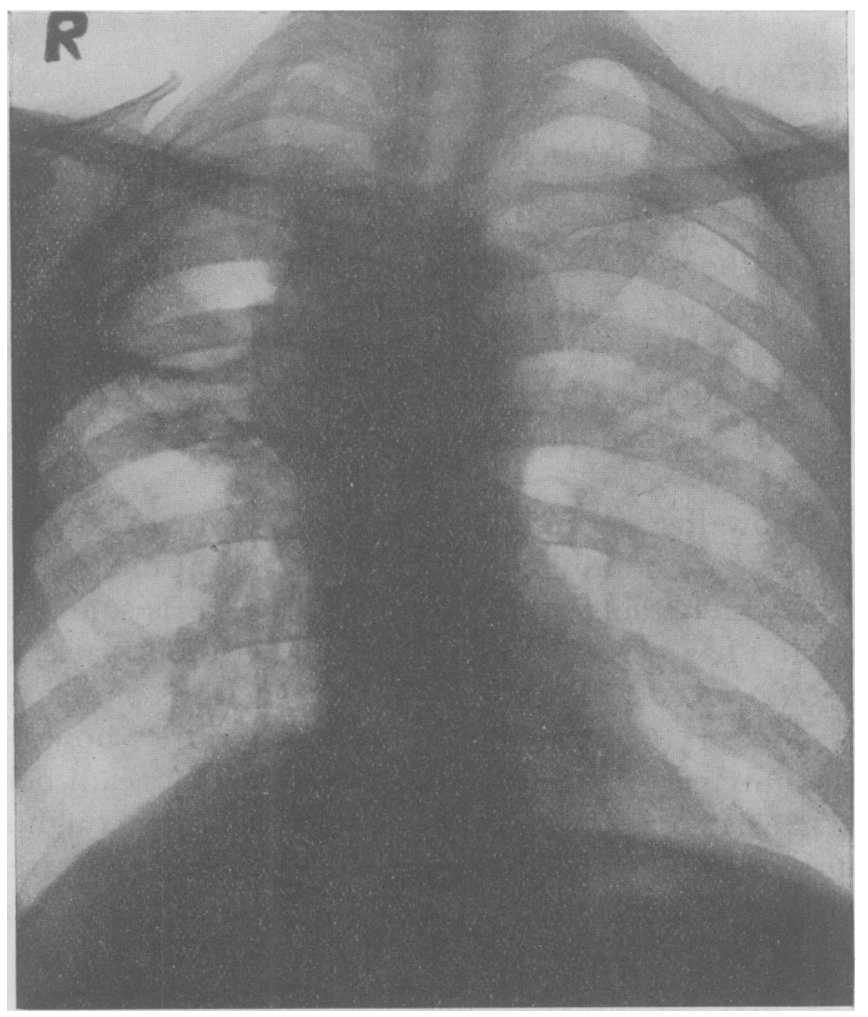

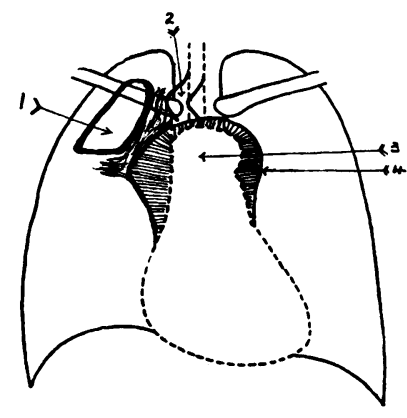

1, Large tuberculosis cavity. 2, Trachea drawn over towards cavity by the fibrosis. 3, Normal width of aorta. 4, Width of aorta in this case.

" Diagrams published, with acknowledgments to Messrs. H. K. Lewis and Co."

In regard to the X-ray examination of the chest, I showed the skiagram to a number of candidates and I found that many were unable to interpret it correctly. This form of examination has now become so important in chest diseases that it is essential that the clinician should be able to interpret his own films. The print and illustrated diagram indicate the essential points in the film. Finally, with regard to "treatment." Few candidates were absolutely familiar with the routine treatment of a case of chronic pulmonary tuberculosis. For instance, the full meaning of "sanatorium treatment" 
and what it implies appeared to be little understood. On the use of the term "absolute rest" candidates were vague.

Concerning the more recent advances, such as collapse therapy, they were not as familiar as they might have been with the detailed account of the procedure and technique. Take, for example, phrenic evulsion. It was generally known that the phrenic nerve was evulsed, but how one proceeded to get at the phrenic nerve appeared to baffle a number of students. One perhaps ought to admit that the case was not a straightforward chest case, but correct routine examination would have produced more satisfactory results. Finally, whilst the general principles may be understood, detailed knowledge of procedure is expected in an examination of the standard of the M.R.C.P.

\section{INTRATHORACIC GOITRE.}

\section{BY MAURICE DAVIDISON, M.D., F.R.C.P., Physician, Brompton Hospital and Miller General Hospital.}

OF the purely medical aspects of intrathoracic goitre there is indeed little to be said; the duties of the physician in such cases are mainly concerned with the question of differential diagnosis. It is therefore of importance to consider the general clinical picture likely to be presented by a patient suffering from a hidden goitre, and to emphasize such points as may enable us to distinguish this condition from other forms of intrathoracic tumour.

The growth of thyroid tissue below the sternum is not a common phenomenon; true intrathoracic goitre is an extremely rare condition. 'Joll,' in his recent monograph, has pointed out the looseness with which the term intrathoracic goitre is sometimes used in the literature of the subject and has classified these tumours into four varieties : (I) Intrathoracic goitre proper; (2) mediastinal goitre; (3) goitre plongeant; (4) substernal goitre. He makes it clear that the term substernal goitre should be reserved for those growths which are only partly intrathoracic, the goitre plongeant being ordinarily intrathoracic, though it may be forced upwards into the neck by coughing, straining, and so forth. It is the first two varieties which are most likely to give rise to difficulty in diagnosis; such cases may demand no little consultation and necessitate much team work between physician, surgeon and radiologist.

The first point on which we may lay stress is that the symptoms in cases of intrathoracic goitre, of whatever variety, are mainly those caused by pressure of the mass on surrounding structures, and that although, as in any form of thyroid enlargement, toxic symptoms may make their appearance, these are not nearly so prominent

Symptoms and Signs. other forms of hyperthyroidism associated with a visible tumour. Pressure symptoms in cases of hidden goitre do not differ essentially from those met with in any other kind of intrathoracic tumour, but are more likely to appear as early

' Joll, C. A. "Diseases of the Thyroid Gland." London, 1932. Heinemann, Ltd. 